DOI: 10.12731/2070-7568-2017-2-132-145

УДК 339

\title{
ОЦЕНКА ЭКОНОМИЧЕСКОЙ ЭФФЕКТИВНОСТИ ОКАЗАНИЯ АУТСОРСИНГОВЫХ УСЛУГ В СФЕРЕ ВНЕШНЕЭКОНОМИЧЕСКОЙ ДЕЯТЕЛЬНОСТИ ПРЕДПРИЯТИЙ
}

\author{
Грачева Е.С., Ермакова Е.A.
}

Несмотря на то, что аутсорсинговые предприятия на российском рынке услуг появились с началом рыночных отношений, существует не так много научных исследований, касаюшихся вопросов конкуренции и экономической оценки оказания аутсорсинговых услуг в сфере ВЭД.

Экономическая интеграция российского бизнеса в международные экономические отношения приводит к усложнению всего национального ВЭК (внешнеэкономического комплекса) и к необходимости развития внешнеэкономической инфраструктуры. Одним из важнейших ее элементов являются услуги по выполнению как вспомогательных внешнеэкономических операчий (переводческие, транспортные, таможенные и пр.), так и ведение ВЭД за предприятие-клиента (комплексный аутсорсинг ВЭД).

В настоящее время сложились благоприятные условия для развития аутсорсингового бизнеса в сфере ВЭД, что обусловливает необходимость более детального изучения данного вида хозяйственной деятельности и разработки системы показателей оценки экономической эффективности аутсорсинга ВЭД.

Цель - дать характеристику комплексного аутсорсинга ВЭД, разработать систему оченки показателей экономической эффективности оказания услуг аутсорсинга ВЭД.

Метод или методология проведения работы: при написании статьи нашли применение такие научные методы как функциональный и статистический. 
Результаты: дано авторское определение комплексному аутсорсингу ВЭД, разработана система показателей оченки экономической эффективности аутсросинга.

Область применения результатов: результать исследования могут быть полезны предприятиям, оказывающим аутсорсинговые и посреднические услуги в сфере внешнеэкономической деятельности.

Ключевые слова: аутсорсинг внешнеэкономической деятельности; транзакционные издержки; оченка эффективности аутсорсинга.

\section{COST-EFFECTIVENESS ANALYSIS OF OUTSOURCING SERVICES IN REGARD TO FOREIGN ECONOMIC ACTIVITY OF ENTERPRISES}

\section{Gracheva E.S., Ermakova E.A.}

Despite enterprises, which render outsourcing services, appeared on the Russian services market with the beginning of market relations, there are not many researches that deal with competition and cost-effectiveness analyses of outsourcing services in regard to foreign economic activity.

Economic integration of Russian business into international economic relations leads to complication of all national foreign economic complex and to the necessity of international economic infrastructure development. One of its most important parts are both services which deal with execution of support international economic operations (interpreting and translation services, transport services, customs services etc.) and conducting foreign economic activity for client-enterprise (complex outsourcing FEA).

Welcoming environment is formed nowadays for outsourcing business development in regard to foreign economic activity. It dictates the need for more thorough study of this type of business activity and development of indicators system for cost-effectiveness analysis of outsourcing in regard to foreign economic activity. 
Purpose - to define the complex outsourcing FEA, to develop the indicators system for cost-effectiveness analysis of outsourcing services in regard to foreign economic activity.

Methodology: in article following scientific methods are used: functional method and statistical method.

Results: is given authorial definition of complex outsourcing FEA, is developed the indicators system for cost-effectiveness analysis of outsourcing.

Practical implications: the results of this research may be used by the businesses, which render outsourcing and intermediary services in regard to foreign economic activity.

Keywords: outsourcing of foreign economic activity; transaction costs; cost-effectiveness analyses of outsourcing.

Предприятиям, имеющим небольшой опыт деятельности в таких сферах, как таможенное оформление, экспорт товаров, организация международных грузоперевозок, весьма сложно самостоятельно разобраться во всех нюансах и тонкостях отечественного, а тем более, иностранного таможенного законодательства. Наилучшим решением в подобной ситуации становится аутсорсинг ВЭД.

Аутсорсинг (out - внешний, source - источник) - передача opганизацией определенных бизнес-процессов и производственных функций на обслуживание другой компании, специализирующейся в соответствующей области [1].

Курбанов А.Х. и Котляров И.Д. в своих трудах предлагают следующие определения данной экономической категории:

«Аутсорсинг - способ оптимизации деятельности филиалов за счет концентрации усилий на осуществлении основных видов деятельности и передачи выполнения отдельных видов работ (услуг) специализированным организациям (индивидуальным предпринимателям) на договорной основе с соответствующим сокращением персонала филиалов» [2].

«Аутсорсинг - одна из стратегических альтернатив, направленная на привлечение внешних ресурсов вместо осуществления работы собственными силами» [3]. 
К услугам аутсорсинговых компаний целесообразно прибегать в том случае, если:

- объем и периодичность поставок относительно невелики содержание собственной логистической службы и службы ВЭД экономически не оправданно;

- менеджмент предприятия придерживается стратегии концентрации всех ресурсов на профильной для него деятельности;

- планируется сокращение финансовых и временных затрат на содержание логистической службы и службы ВЭД на предприятии [4].

Среди положительных последствий использования услуг аутсорсинговых компаний чаще всего называют:

1) сокращение запасов и «замороженных» денег;

2) высокая готовность товара к поставке;

3) сокращение времени выполнения заказа и повышение его качества;

4) повышение гибкости производства;

5) снижение себестоимости продукции;

6) сокращение издержек обращения и транзакционных издержек;

7) ускорение оборачиваемости капитала [5].

Одним из преимуществ аутсорсинга является многообразие оказываемых услуг, возможность их различной комбинации, встраивание посредника во внешнеторговые операции клиента на разных стадиях контрактации международной торговой сделки (таблица 1).

Таблица 1.

Классификация услуг аутсорсинга ВЭД $[3,4,5,6,7,8]$

\begin{tabular}{|l|l|}
\hline $\begin{array}{c}\text { Направление } \\
\text { аутсорсинга ВЭД } \\
\text { предприятия }\end{array}$ & \multicolumn{1}{|c|}{ Содержание } \\
\hline $\begin{array}{l}\text { ИТ-аутсорсинг } \\
\text { (ІТО) }\end{array}$ & $\begin{array}{l}\text { - создание веб-ресурсов, интернет-магазинов, электрон- } \\
\text { ных торговых площадок; } \\
\text { - разработка, установка, сопровождение ПО, необходимо- } \\
\text { го для ведения ВЭД; } \\
\text { - обслуживание техники сторонними специализирован- } \\
\text { ными компаниями. }\end{array}$ \\
\hline
\end{tabular}


Окончание табл. 1.

\begin{tabular}{|c|c|}
\hline $\begin{array}{l}\text { Консультационный } \\
\text { аутсорсинг }\end{array}$ & $\begin{array}{l}\text { - поиск потенциальных внешнеторговых партнеров; } \\
\text { - составление внешнеторговых контрактов в соответствии } \\
\text { с особенностями национального законодательства стран } \\
\text { партнеров; } \\
\text { - переводческие услуги. }\end{array}$ \\
\hline $\begin{array}{l}\text { Аутсорсинг в сфере } \\
\text { международного } \\
\text { маркетинга }\end{array}$ & $\begin{array}{l}\text { - анализ внутренней среды, оценка конкурентного потен- } \\
\text { циала предприятия с точки зрения целесообразности вы- } \\
\text { хода на внешний рынок; } \\
\text { - осуществление процедуры отбора зарубежных рынков, } \\
\text { анализ и оценка перспектив присутствия предприятия- } \\
\text { клиента на новом географическом рынке; } \\
\text { - разработка стратегии продвижения товара предприятия- } \\
\text { клиента на новые рынки, проведение рекламных акций, } \\
\text { РR- компаний, стимулирование продаж, формирование } \\
\text { позитивного имиджа предприятия на зарубежном рынке } \\
\text { (связи с общественностью); } \\
\text { - выявление новых потребностей потребителей на зару- } \\
\text { бежных рынках, оценка уровня удовлетворенности каче- } \\
\text { ством товаров; } \\
\text {-оценка и прогнозирование конкурентных позиций пред- } \\
\text { приятия-клиента на зарубежном рынке. }\end{array}$ \\
\hline $\begin{array}{l}\text { Аутсорсинг в } \\
\text { сфере таможенного } \\
\text { оформления и } \\
\text { обложения товаров }\end{array}$ & $\begin{array}{l}\text { - услуги по таможенному оформлению товаров (сбор и } \\
\text { оформление необходимой таможенной документации, декла- } \\
\text { рирование товара, оплата таможенных пошлин и сборов); } \\
\text { - консультационные услуги (определение кода товара в } \\
\text { соответствии с ТН ВЭД ЕАЭС, выбор оптимального та- } \\
\text { моженного режима и т.д.); } \\
\text { - услуги по таможенной перевозке; } \\
\text { - услуги по хранению товаров на собственном складе и СВХ. }\end{array}$ \\
\hline $\begin{array}{l}\text { Транспортно- } \\
\text { логистический } \\
\text { аутсорсинг }\end{array}$ & $\begin{array}{l}\text { - международная перевозка грузов; } \\
\text { - хранение, складирование товаров, упаковочно-маркиро- } \\
\text { вочные операции; } \\
\text { - экспедирование товаров; } \\
\text { - управление цепями поставок, разработка оптимальных } \\
\text { маршрутов перевозки. }\end{array}$ \\
\hline $\begin{array}{l}\text { Аутсорсинг в } \\
\text { сфере финансового } \\
\text { обеспечения ВЭД } \\
\text { клиента }\end{array}$ & $\begin{array}{l}\text { - проведение платежно-расчетных операций от имени и } \\
\text { поручению я клиента; } \\
\text { - выбор оптимальной формы и способа международных } \\
\text { расчетов; } \\
\text { - финансирование внешнеторговых операций клиента } \\
\text { (краткосрочные кредиты, факторинговые и форфейтинго- } \\
\text { вые операции, делькредере и пр.); } \\
\text { - контроль исполнения финансовых обязательств внешне- } \\
\text { торговых партнеров клиента. }\end{array}$ \\
\hline
\end{tabular}


Аутсорсинговая компания может оказывать услуги консультационного характера или взять на себя выполнение всех работ по контрактации внешнеторговой сделки, нередки случаи, когда к услугам аутсорсинга прибегают только на стадии исполнения сделки для транспортно-экспедиторского сопровождения или таможенного оформления товаров.

Одновременное оказание всех видов аутсорсинговых услуг предполагает выстраивание долгосрочных устойчивых отношений между посредником и клиентом, можно говорить о комплексном аутсорсинге ВЭД, когда аутсорсер выполняет функции удаленного отдела ВЭД, но интегрированного в организационную структуру предприятия. Исходя из вышеизложенного, можно дать следующее определение комплексному аутсорсингу внешнеэкономической деятельности.

Комплексный аутсорсинг ВЭД - вид хозяйственной деятельности, заключающийся в оказании профессиональных услуг по выполнению организационно-экономических и оперативно-коммерческих внешнеэкономических функций в сфере внешнеэкономической (в т.ч. внешнеторговой) деятельности на основании договорных отношений между аутсорсером и киентом.

Предоставление аутсорсинговых услуг на стадии заключения и исполнения внешнеторгового контракта можно с определенной долей условности отнести к международным торгово-посредническим операциям. В соответствии с общепринятой классификацией международных торговых посредников в зависимости от комплексности услуг аутсорсинговой компании данные операции относятся к комиссионным, консигнационным или агентским операциям.

Суть комиссионных операций состоит в том, что комитент (собственник товара) поручает комиссионеру (посреднику) от имени комиссионера, но за счет комитента совершить операцию купли-продажи с третьим контрагентом. С комитентом комиссионер строит свои отношения на основании договора комиссии. 
По договору консигнации, который представляет собой разновидность договора комиссии, принципал (консигнант) поставляет товары на склад агента (консигнатора) для их последующей реализации на рынке консигнатора. Консигнант является собственником товара до момента его реализации.

Агентские операции в торговле состоят в поручении одной стороной, именуемой принципалом (доверитель), независимой от нее другой стороне, именуемой агентом (торговым, коммерческим), совершение фактических и юридических действий, связанных с продажей или покупкой товара на оговоренной территории за счет и от имени принципала. Агентские операции совершаются на основе агентского договора.

Экономический результат аутсорсинговых компаний складывается как сумма вознаграждений предприятий-клиентов, рассчитываемая в процентах от сумм сделок, совершаемых по их поручению. Исключение составляют такие разновидности аутсорсинга ВЭД как транспортный и IT-аутсорсинг.

Вопросам оценки эффективности оказания услуг аутсорсинга как для самих фирм-аутсорсеров, так и для их заказчиков, посвящены работы многих российских ученых-экономистов $[9,10$, $11,12]$.

Для предприятий, оказывающих услуги комплексного аутсорсинга ВЭД, можно предложить следующую систему показателей оценки экономической эффективности их деятельности.

Показатели первой группы характеризуют динамику аутсорсинговых услуг и дают количественную оценку экономического эффекта деятельности аутсорсинговых компаний.

Показатели второй группы характеризуют экономический эффект от аутсорсинга ВЭД, выражающийся в размере и доле прибыли от аутсорсинга в общем финансовом результате компании.

Показатели третьей группы дают оценку экономической эффективности аутсорсинга на основе показателей рентабельности и эффективности. 
Таблицуа 2.

\section{Предлагаемая система показателей оценки эффективности услуг аутсорсинга ВЭД}

\begin{tabular}{|c|c|c|}
\hline Показатель & Формула расчета & $\begin{array}{c}\text { Экономическое содер- } \\
\text { жание }\end{array}$ \\
\hline 1 & 2 & 3 \\
\hline \multicolumn{3}{|c|}{ Показатели первой группь - начальный экономический результат } \\
\hline $\begin{array}{l}\text { Стоимостной объ- } \\
\text { ем аутсорсинговых } \\
\text { услуг }(A), \text { руб. }\end{array}$ & $\begin{array}{l}\qquad A=\sum_{i=1}^{N} q_{i} \times Ц_{A}, \\
\text { где } A-\text { стоимостной объем аутсорсин- } \\
\text { говых услуг; } \\
q_{i}-\text { количество наименований предо- } \\
\text { ставляемых услуг; } \\
\bigsqcup_{A}-\text { цена предоставляемой услуги; } \\
N-\text { количество предприятий-клиентов }\end{array}$ & $\begin{array}{l}\text { Характеризует стоимост- } \\
\text { ной объем аутсорсинго- } \\
\text { вых услуг }\end{array}$ \\
\hline $\begin{array}{l}\text { Коэффициент из- } \\
\text { менения объема } \\
\text { аутсорсинговых ус- } \\
\text { луг }\left(K_{A}\right)\end{array}$ & $\begin{array}{c}K_{A}=A_{1} / A_{2}, \\
\text { где } A_{1}-\text { стоимостной объем аутсорсин- } \\
\text { говых услуг за анализируемый период; } \\
A_{2}-\text { стоимостной объем аутсорсинго- } \\
\text { вых услуг базового периода. }\end{array}$ & $\begin{array}{l}\text { Характеризует динамику } \\
\text { аутсорсинговых услуг }\end{array}$ \\
\hline $\begin{array}{l}\text { Коэффициент } \\
\text { структуры аутсор- } \\
\text { синговых услуг } \\
\left(Д_{A}\right), \%\end{array}$ & $\begin{array}{l}\qquad Д_{A}=(A / T) \times 100 \%, \\
\text { где } A-\text { стоимость услуг, оказанных од- } \\
\text { ному предприятию - клиенту; } \\
T-\text { стоимость всех оказанных аут- } \\
\text { сорсинговых услуг в анализируемом } \\
\text { периоде. }\end{array}$ & $\begin{array}{l}\text { Характеризует структуру } \\
\text { продаж аутсорсинговых } \\
\text { услуг }\end{array}$ \\
\hline $\begin{array}{l}\text { Коэффициент об- } \\
\text { новления аутсор- } \\
\text { синговых услуг } \\
\left(Д_{\text {н.A.y. }}\right), \%\end{array}$ & 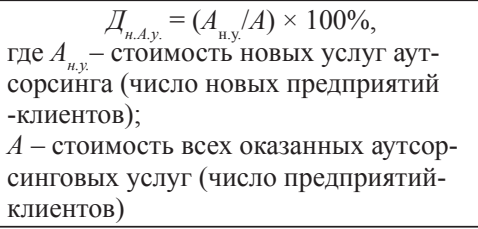 & $\begin{array}{l}\text { Характеризует уровень } \\
\text { обновления ассортимента } \\
\text { услуг аутсорсинга (кли- } \\
\text { ентской сети) }\end{array}$ \\
\hline \multicolumn{3}{|c|}{ Показатели второй группы - экономический эффект } \\
\hline $\begin{array}{l}\text { Прибыль от продаж } \\
\text { аутсорсинговых ус- } \\
\text { луг }\left(\Pi_{A}\right), \text { руб. }\end{array}$ & $\begin{array}{l}\qquad \Pi_{A}=B_{A}-3_{A}, \\
\text { где } B_{A}-\text { выручка от продажи аутсор- } \\
\text { синговых услуг; } \\
3_{A}-\text { затраты на оказание аутсорсинго- } \\
\text { вых услуг (затраты на изучение рынка, } \\
\text { рекламу, транспортно-экспедиторские, } \\
\text { расходы на заключение сделки, пла- } \\
\text { тежно-расчетные операции, таможен- } \\
\text { ные пошлины и сборы и др.). }\end{array}$ & $\begin{array}{l}\text { Характеризует прибыль } \\
\text { от продаж услуг аутсор- } \\
\text { синга }\end{array}$ \\
\hline $\begin{array}{l}\text { Коэффициент изме- } \\
\text { нения прибыли }\left(K_{A}\right)\end{array}$ & $\begin{array}{l}K_{A}=\Pi_{1} / \Pi_{2}, \\
\text { где } \Pi_{1}-\text { прибыль анализируемого пе- } \\
\text { риода; } \\
\Pi_{2}-\text { прибыль базового периода. }\end{array}$ & $\begin{array}{l}\text { Характеризует динамику } \\
\text { прибыли, полученной от } \\
\text { оказания аутсорсинговых } \\
\text { услуг }\end{array}$ \\
\hline
\end{tabular}


Окончание табл. 2.

\begin{tabular}{|l|l|l|}
\hline $\begin{array}{l}\text { Коэффициент } \\
\text { структуры прибыли } \\
\left(Д_{n . A}\right), \%\end{array}$ & \begin{tabular}{l}
\multicolumn{1}{|c|}{$Д_{n .4}=\left(\Pi_{A} / \Pi\right) \times 100 \%}$, \\
где $\Pi_{A}-$ прибыль от оказания аутсор- \\
синговой услуги (полученная от кон- \\
кретного клиента); \\
$\Pi$ - общая прибыль от аутсорсинго- \\
вой деятельности (полученная от всех \\
клиентов $).$
\end{tabular} & $\begin{array}{l}\text { Позволяет определить } \\
\text { значимость различных } \\
\text { источников прибыли } \\
\text { от аутсорсинговой дея- } \\
\text { тельности (в разрезе на- } \\
\text { правлений аутсорсинга и } \\
\text { предприятий-клиентов })\end{array}$ \\
\hline \multicolumn{2}{|c|}{ Показатели третьей группь -экономическая эффективность } \\
\hline $\begin{array}{l}\text { Рентабельность за- } \\
\text { трат аутсорсинга } \\
\left(R_{3}\right), \%\end{array}$ & \multicolumn{1}{|c|}{$R_{3}=\left(\Pi_{A} / 3_{A}\right) \times 100 \%$} & $\begin{array}{l}\text { Характеризует уровень } \\
\text { прибыли с рубля затрат } \\
\text { на оказание аутсорсинго- } \\
\text { вых услуг }\end{array}$ \\
\hline $\begin{array}{l}\text { Рентабельность } \\
\text { продаж }\left(R_{n p}\right), \%\end{array}$ & $\begin{array}{l}\text { Характеризует уровень } \\
\text { прибыли, получаемой с } \\
\text { рубля продаж аутсорсин- } \\
\text { говых услуг }\end{array}$ \\
\hline
\end{tabular}

Важнейшим фактором прибыльности и конкурентоспособности аутсорсинговой компании является цена оказываемых ею услуг. Как показывает практика, за предоставление комплексных аутсорсинговых услуг ВЭД компании-клиенты уплачивают согласованный процент от сумм внешнеторговых контрактов. В этот процент закладываются все затраты, понесенные фирмой-агентом и планируемая к получению прибыль. В затраты включаются все консультационные, транзакционные, логистические издержки, а также накладные расходы аутсорсинговой фирмы. Каждый пример сотрудничества с аутсорсинговой фирмой при предоставлении комплексных аутсорсинговых услуг отличается индивидуальным набором форматов этого сотрудничества, разной степенью взаимозависимости бизнесов принципала и агента, в связи с чем, процент, получаемый аутсорсинговой компанией, может колебаться от нескольких промилле до 5\% от суммы заключенной внешнеторговой сделки. В общем и целом рыночная конкурентная среда, а также затраты на самостоятельное ведение ВЭД предприятий-клиентов определяют максимальные уровни цен аутсорсинговых услуг, в то же время собственные затраты и норма прибыли как цена присутствия в аутсорсинговом бизнесе будут определять минимальный процент за предоставление услуг аутсорсинга (1). 


$$
3_{A}<Ц_{A} \leq Ц_{A K} ; 3_{\text {ВэдКл }}
$$

где $3_{A}$ - затраты на оказание аутсорсинговых услуг, руб.;

$Ц_{A}$ - цена аутсорсинговых услуг, руб.

$Ц_{A K}$ - цена на аутсорсинговые услуги фирм-конкурентов, руб.;

$3_{\text {вэдкл }}$ - затраты на самостоятельное ведение ВЭД предприятийклиентов, руб.

Сегодня, в странах с развитой инфраструктурой аутсорсингом внешнеэкономической деятельности постоянно пользуются $80 \%$ организаций и производственных предприятий. Эти показатели растут и в России, чему в значительной мере способствуют изменения в таможенном законодательстве, принятие нового таможенного кодекса, а также масштабная реструктуризация таможенных органов (перенос на границу таможенного оформления, внедрение новых технологий с использованием Интернета и др.). К наиболее представительным компаниям аутсорсингового бизнеса в сфере ВЭД можно отнести: Goodwill, Ваш Импортер, Major, SO-Logistics, OUTVED и др.

Таким образом в настоящей статье на основе анализа российской практики оказания аутсорсинговых услуг и изучения научной литературы по данной тематике, были систематизированы услуги, предоставляемые в рамках аутсорсинга ВЭД. Предложена авторское определение понятию «комплексный аутсорсинг ВЭД», разработана система оценки эффективности оказания аутсорсинговых услуг.

\section{Список литературы}

1. Вишнякова О.И. Аутсорсинг внешнеэкономической деятельности предприятий // Евразийский Союз Ученых (ЕСУ). 2016. № 6 (27). URL: http://euroasia-science.ru/ekonomicheskie-nauki/autsorsingvneshneekonomicheskoj-deyatelnosti-predpriyatij / (дата обращения: 30.03.2017).

2. Курбанов А.Х., Плотников В.А. Аутсорсинг: история, методология, практика. М.: Инфра-М, 2011. 112 с.

3. Котляров И.Д. Сущность аутсорсинга как организационно-экономического явления // Компетентность. 2012. № 5. С. 28-35. 
4. Савинов Ю.А. Аутсорсинг в международной торговле // Российский внешнеэкономический вестник. 2006. № 4. С. 3-13.

5. Тушавин В.А. Особенности аутсорсинга в сфере информационнокоммуникационных технологий // Менеджмент и бизнес-администрирование. 2014. № 1. С. 79-86.

6. Котляров И.Д. Анализ экономической и организационной сущности современных форм финансового предпринимательства // Корпоративные финансы. 2010. № 3. С. 104-112.

7. Луцкая Н.В. Аутсорсинг: уровни предоставляемых услуг и модели взаимодействия сторон// Компетентность. 2016. №2(133). C. $28-34$.

8. Луцкая Н.В Аутсорсинг и инсорсинг как взаимодополняющие инструменты менеджмента для формирования оптимальной организационной структуры предприятий// Организатор производства. 2016. № 2 (69). С. 41-57.

9. Курбанов А.Х. Методика оценки целесообразности использования аутсорсинга // Современные проблемы науки и образования. 2012. № 1. C. 231.

10.Курбанов А.X. Методика оценки эффективности деятельности сторонних организаций, привлекаемых в рамках аутсорсинговых контрактов // Фундаментальные исследования. 2012. № 6-1. C. 239-243.

11. Котляров И.Д. Проблемы оценки экономического эффекта аутсорсинга // Проблемы экономики и управления нефтегазовым комплексом. 2013. № 6. С. 9-13.

12. Котляров И.Д. Принятие аутсорсером решения о сотрудничестве с заказчиком на основе критерия ожидаемого экономического эффекта // Проблемы экономики и управления нефтегазовым комплексом. 2013. № 7. C. 15-20.

\section{References}

1. Vishnyakova O.I. Autsorsing vneshneehkonomicheskoj deyatelnosti predpriyatij [Outsourcing of foreign economic activity of enterprises]. Evrazijskij Soyuz Uchenyh (ESU) [Eurasian Union of Scientists]. 2016. 
№ 6 (27). http://euroasia-science.ru/ekonomicheskie-nauki/autsorsing-vneshneekonomicheskoj-deyatelnosti-predpriyatij (accessed date: 30.03.2017).

2. Kurbanov A.H., Plotnikov V.A. Autsorsing: istorija, metodologija, praktika [Outsourcing: history, methodology, practice]. M.: Infra-M, 2011. $112 \mathrm{~s}$.

3. Kotljarov I.D. Sushhnost' autsorsinga kak organizacionno-jekonomicheskogo javlenija [The essence of outsourcing as an organizational and economic phenomenon]. Kompetentnost' [Competence]. 2012. № 5, pp. 28-35.

4. Savinov Ju.A. Autsorsing v mezhdunarodnoj torgovle [Outsourcing in International Trade]. Rossijskij vneshnejekonomicheskij vestnik [The Russian Foreign Economic Bulletin]. 2006. № 4, pp. 3-13.

5. Tushavin V.A. Osobennosti autsorsinga v sfere informacionno-kommunikacionnyh tehnologij [Features of outsourcing in the field of information and communication technologies]. Menedzhment $i$ biznes-administrirovanie [Management and Business Administration]. 2014. № 1, pp. 79-86.

6. Kotljarov I.D. Analiz jekonomicheskoj i organizacionnoj sushhnosti sovremennyh form finansovogo predprinimatel'stva [Analysis of the economic and organizational nature of modern forms of financial entrepreneurship]. Korporativnye finansy [Corporate Finance]. 2010. № 3, pp. 104-112.

7. Luckaja N.V. Autsorsing: urovni predostavljaemyh uslug i modeli vzaimodejstvija storon [Outsourcing: levels of services provided and models of interaction between the parties]. Kompetentnost' [Competence]. 2016. №2(133), pp. 28-34.

8. Luckaja N.V Autsorsing i insorsing kak vzaimodopolnjajushhie instrumenty menedzhmenta dlja formirovanija optimal'noj organizacionnoj struktury predprijatij [Outsourcing and insourcing as complementary management tools for the formation of the optimal organizational structure of enterprises]. Organizator proizvodstva [Production Organizer]. 2016. № 2 (69), pp. 41-57.

9. Kurbanov A.H. Metodika ocenki celesoobraznosti ispol'zovanija autsorsinga [Methodology for evaluating the appropriateness of using out- 
sourcing]. Sovremennye problemy nauki i obrazovanija [Modern problems of science and education]. 2012. № 1. P. 231.

10. Kurbanov A.H. Metodika ocenki jeffektivnosti dejatel'nosti storonnih organizacij, privlekaemyh v ramkah autsorsingovyh kontraktov [Methodology for evaluating the performance of third-party organizations involved in outsourcing contracts]. Fundamental 'nye issledovanija [Basic research]. 2012. № 6-1, pp. 239-243.

11. Kotljarov I.D. Problemy ocenki jekonomicheskogo jeffekta autsorsinga [The problems of assessing the economic effect of outsourcing]. Problemy jekonomiki i upravlenija neftegazovym kompleksom [Problems of Economics and Management of the Oil and Gas Complex]. 2013. № 6, pp. 9-13.

12. Kotljarov I.D. Prinjatie autsorserom reshenija o sotrudnichestve s zakazchikom na osnove kriterija ozhidaemogo jekonomicheskogo jeffekta [The outsourcing of the decision on cooperation with the customer on the basis of the criterion of expected economic effect]. Problemy jekonomiki i upravlenija neftegazovym kompleksom [Problems of Economics and Management of the Oil and Gas Complex]. 2013. № 7, pp. 15-20.

\section{ДАННЫЕ ОБ АВТОРАХ}

Грачева Евгения Сергеевна, доцент кафедры «Мировая экономика и менеджмент», кандидат экономических наук Самарский институт (филиал) РЭУ им. Г.В. Плеханова ул. Неверова, 87, г. Самара, Самарская область, 443036, Российская Федерация evgegrachova2008@yandex.ru

Ермакова Евгения Александровна, магистрант направления Экономика, магистерская программа Мировая экономика и международный бизнес

Самарский институт (филиал) РЭУ им. Г.В. Плеханова ул. Неверова, 87, г. Самара, Самарская область, 443036, Российская Федерация evgegrachova2008@yandex.ru 


\section{DATA ABOUT AUTHORS}

Gracheva Evgenia Sergeevna, Associate Professor of the Department "World Economy and Management", Candidate of Economic Sciences

Samara Institute (Branch) of Russian State University of Trade and Economics (SI REU)

87, Neverov, Samara, Samara Region, 443036, Russian Federation

evgegrachova2008@yandex.ru

Ermakova Evgeniya Alexandrovna, Master of Economics, Master's Program World Economy and International Business

Samara Institute (Branch) of Russian State University of Trade and Economics (SI REU)

87, Neverov, Samara, Samara Region, 443036, Russian Federation

evgegrachova2008@yandex.ru 